\title{
From Knowing-About To Knowing-To: Development Of Engineering Pedagogical Content Knowledge By Elementary Teachers Through Perceived Learning And Implementing Difficulties
}

Yan Sun, University of West Alabama, USA

Johannes Strobel, Texas A\&M University, USA

\begin{abstract}
The present study sought to reveal how elementary teachers develop their engineering pedagogical content knowledge (PCK) after leaving professional development programs to practice engineering teaching in real classroom settings. Participants of this study were the elementary teachers who received one-week training of engineering education provided by EfF ( a P-12 Engineering teaching and learning institute in a Midwestern university). Data of this study were collected from these elementary teachers through face-to-face interviews and an online open-ended survey. Based on a phenomenological research method and a constructivist ELC (engineering instruction, learners, and contexts) framework developed by the researchers to investigate engineering PCK development, this study explored the elementary teachers' lived engineering teaching experiences following the procedures of inductive qualitative data analysis. Findings yielded in this study revealed that the elementary teachers developed their knowledge about engineering teaching and learning situations through their engineering teaching practice. But such knowledge was the knowledge of knowing-about and it did not automatically transfer into the elementary teachers' engineering PCK or knowing-to knowledge allowing them to act effectively and responsively to engineering teaching and learning situations at hand. In their engineering teaching practice, the elementary teachers engaged themselves in a dynamic and evolving trial-failure-success process. It was in this process that the elementary teachers made sense of new engineering teaching and learning situations and transformed their knowing-about into engineering PCK responsive to these situations.
\end{abstract}

Keywords: Engineering PCK; Elementary Engineering Education; Teacher Professional Development

\section{INTRODUCTION}

hile the adequacy of supply and the quality of the workforce in the Science, Technology, Engineering, and Mathematics (STEM) fields have long been recognized as the long-term key to U.S. economic competitiveness and growth, there has been an increasing national concern about the shrinking STEM workforce pipeline (Jobs for the Future, 2007). Students are discouraged from entering the STEM pipeline due to either inadequate preparation in math and science or poor teacher quality in their K-12 education (ACT, 2006). Those who are academically qualified for postsecondary studies in STEM fields turn to other fields for various reasons such as high tuition and demanding curricula and courses of study (American Association of State Colleges and Universities, 2005). In the field of engineering, the trends in undergraduate and graduate enrollment in engineering science are troubling (U.S. Government Accountability office, 2005). The dramatic decrease in the number of engineers graduating from U.S. institutions has given rise to the warning by the Business Roundtable (2005) that if this trend continues, more than $90 \%$ of all scientists and engineers in the world will live in Asia. 
With a strong emerging consensus among scientific, business, and education leaders that "America's ability to innovate and compete in the global marketplace is directly tied to the ability of our public schools to adequately prepare all of our children in STEM" (NGA Reports, 2007, p. 4), efforts have been made to integrate engineering into K-12 education. Although experts agree that we must start in elementary schools to capture and maintain students in the STEM field, most outreach programs target high school students and "less attention has been paid to elementary and middle school students, where efforts would serve a 'mainline' function of promoting technological literacy and stimulating interests in mathematics and science" (National Academy of Engineering, 2008, p. 4).

Given the relatively small amount of attention paid to elementary engineering education, and the misalignment of STEM coursework and expectations between elementary, middle, and high schools (NGA, 2007), more efforts are necessary to target the elementary student population. One large step toward accomplishing this goal was the development of the Engineering is Elementary (EiE): Engineering and Technology Lessons for Children curriculum by the National Center for Technological Literacy (NCTL) and the NCTL's Pre-College Engineering for Teachers (PCET) summer institutes introducing elementary teachers to engineering using the EiE curriculum. Research has shown that EiE greatly improved elementary students' understanding about technology and engineering (Lachapelle, Cunningham, \& Oware, 2008; Lachapelle, Cunningham, John, Cannady, \& Keenan, 2010), had tremendous appeal among girls and other underrepresented groups in STEM fields (Faux, 2006), and exerted significant impact on students' attitude toward engineering (Cunningham \& Lachapelle, 2010).

Although research also showed that elementary teachers increased their knowledge of engineering and technology through EiE training (Cunningham, Lachapelle, \& Keenan, 2010) and that EiE training had a strong positive impact on participating elementary teachers' instructional behaviors (Carson \& Campbell, 2007), inadequate research attention has been given to elementary teachers' real world engineering teaching practice. Also, little is known how, through engineering teaching practice, elementary teachers construct their knowledge of engineering Pedagogical Content Knowledge (PCK), which was defined in this study as specific engineering teaching strategies and methods making engineering content comprehensible and teachable in elementary classrooms.

Preparing elementary teachers to teach engineering is challenging because most elementary teachers lack preparation and confidence in teaching science (Lee et al., 2008), and most of them regard teaching engineering as terrifying (Cunningham, 2008). Previous EfF research on professional development in elementary engineering education indicated that many elementary teachers were afraid of attempting to teach engineering topics and were uncomfortable about teaching engineering concepts because of many preconceived opinions of engineering (Liu, Carr, \& Strobel, 2009). Given the fact that elementary engineering education is a new phenomenon (Cunningham, 2008) and that elementary teachers are not prepared for engineering education, an understanding of how elementary teachers develop engineering PCK through engineering teaching practice is critical for improving existing and future professional development programs in elementary engineering education. The purpose of this study is to help attain this understanding by investigating how the elementary teachers participating in the EfF's local summer academies at Arlington, TX constructed their engineering PCK through their engineering teaching practice.

Adopting a phenomenological approach, the researchers of this study conducted in-depth face-to-face interviews and an on-line open-ended survey with the elementary teachers and explored their lived engineering teaching experience to find out "how they perceive it, describe it, feel about it, judge it, remember it, make sense of it, and talk about it with others" (Patton, 2002, p. 104) - the "it" denoting engineering PCK. The lived engineering teaching experiences of these teachers were "bracketed, analyzed, and compared" (Patton, 2002, p. 106) to find answers to the research question of "How do elementary teachers construct their engineering PCK through engineering teaching practice?" Based on the ELC framework (explained in detail in the next section) developed by the researchers to guide this study, the above research question of this study has been subdivided into two questions: 1) How do elementary teachers construct engineering PCK in the area where engineering instruction interacts with the learners? 2) How do elementary teachers construct engineering PCK in the area where engineering instruction interacts with classroom and school contexts? 


\section{THEORETICAL FRAMEWORK AND LITERATURE REVIEW}

\section{Pedagogical Content Knowledge (PCK)}

PCK was first proposed by Shulman $(1986,1987)$ as an important framing of teacher knowledge. According to Schulman, PCK includes "an understanding of what makes the learning of specific topics easy or difficult" (1986, p. 9) and PCK is "the capacity of a teacher to transform the content knowledge he or she possesses into forms that are pedagogically powerful and yet adaptive to the variations in ability and background presented by the students" (1987, p. 15). Central to Schulman's conceptualization of PCK is that PCK is learner-targeted or learner-oriented. This learner-oriented perspective runs through later research on PCK or PCK models (see e.g., Ball, Thames, \& Phelps, 2008; Banks, Leach, \& Moon, 2005; Grossman, 1990; Koballa, Gräber, Coleman, \& Kemp, 1999; Magnusson, Krajcik, \& Borko, 1999; Russell \& Martin, 2007; van Driel, de Jong, \& Verloop, 2002).

Knowledge of contexts has long been regarded as closely related to PCK (Cochran, King, \& DeRouiter, 1993; Fernández-Balboa \& Stiehl, 1995; Shulman, 1987). In the Pedagogical Context Knowledge (PCxK) model (Barnet, 1999; Barnet \& Hodson, 2001), the conception of PCK is linked to particular teaching contexts in classrooms. Grossman (1990) listed knowledge of context together with subject matter knowledge and general pedagogical knowledge as three domains influencing PCK. Teachers' beliefs and perceptions of teaching and learning are strongly influenced by contextual parameters of the school culture and the educational system in general (Jimoyiannis, 2010; Siorenta \& Jimoyiannis, 2008). What stands out here is the belief the PCK should always be approached and understood in specific contexts.

We hold the view that an essential part of PCK is a set of instructional methods and strategies used in teaching practice to transform subject matter knowledge (SMK) and to make it comprehensible and teachable in specific teaching situations. Based on this understanding and our constructivist view that knowledge is constructed through real life experiences, we defined engineering PCK in this study as engineering teaching methods and strategies constructed through elementary teachers' real classroom engineering instruction to make engineering content comprehensible and teachable in elementary classrooms.

As illustrated in the theoretical framework (see Figure 1), which we used to guide our investigation of elementary teachers' engineering PCK development, "engineering instruction" stands in the center denoting the main focus of this study. However, instruction is not carried out in a vacuum but in interaction with specific target learners and specific contexts. Informed by previous PCK research literature regarding the learner-oriented perspective towards PCK and the influences of contexts on PCK, we included the "learners" and "contexts" dimensions into our ELC framework.

The ELC framework constructed in this study was intended to guide our investigation of the elementary teachers' practice-based engineering PCK development. As illustrated by the framework, we focused on the elementary teachers' description of their real classroom engineering instruction and looked specifically into the areas where engineering instruction interacted with the "learners" dimension and the "contexts" dimension trying to present a holistic picture about how the elementary teachers constructed their engineering PCK through engineering teaching practice. 


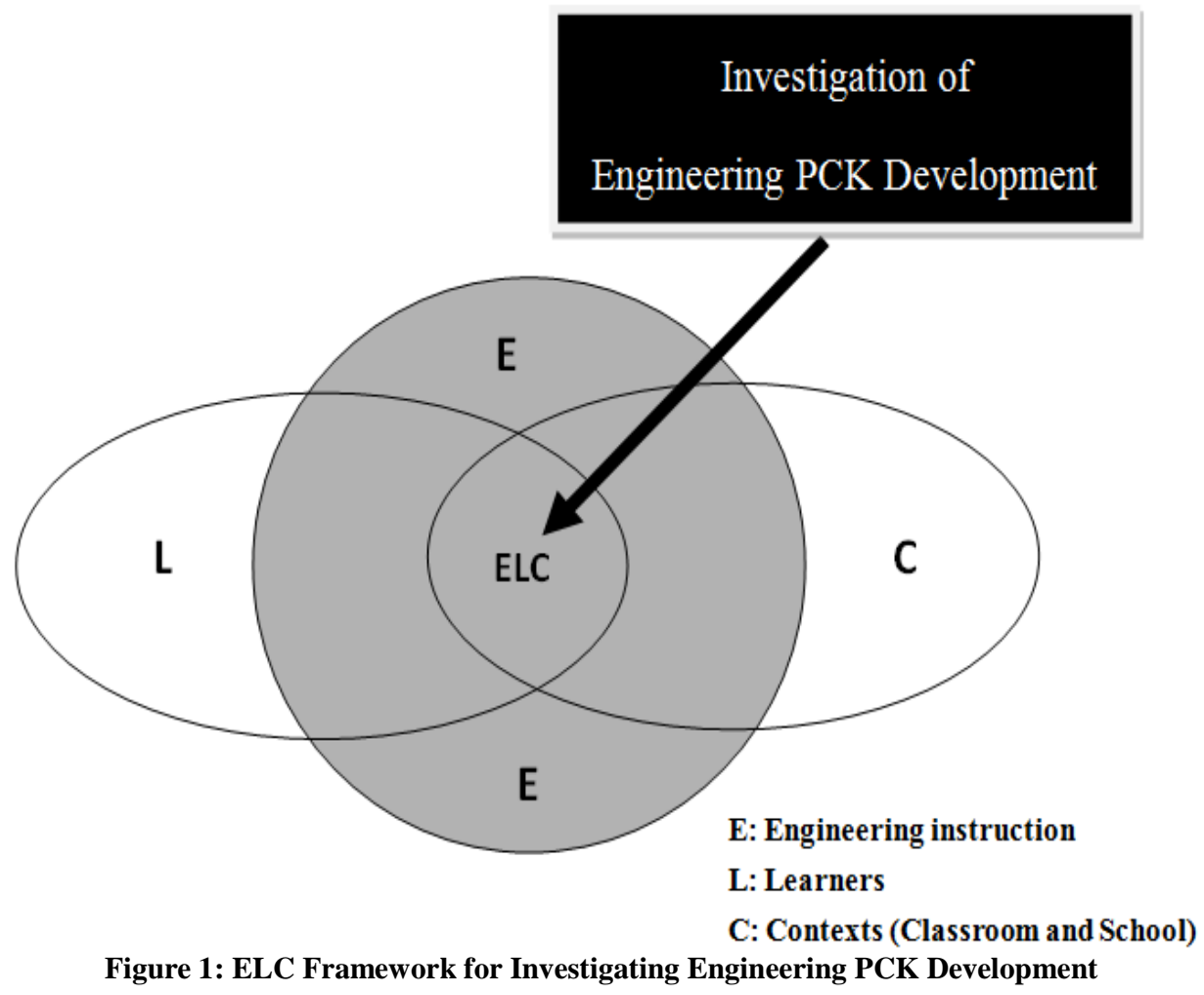

\section{Elementary Teachers and Engineering Education}

Most elementary teachers are not sufficiently prepared to teach science subject matter and lack the necessary scientific skill that would allow them to feel confident about teaching science on a regular basis (Lee et al., 2008; Raizen \& Michelsohn, 1994). Elementary teachers' lack of confidence in teaching science may stem from "a general disinterest in, lack of exposure to, or intimidation by science content" (Buczynski \& Hansen, 2010). Yasar et al.'s survey (2006) showed that, compared to middle school and high school teachers, elementary teachers were least interested in learning design, engineering, and technology (DET) through in-service activities and workshops and scored the importance of DET the lowest. Also, according to the survey, middle and high school teachers are likely to be science specialists more interested in content as opposed to elementary teachers who are generalists interested in children.

According to EiE engineering professional development research, the biggest challenges to integrating engineering into elementary classrooms were elementary teachers' weak science knowledge, their anxiety or fear about engineering, their lack of previous experience with elementary engineering education, and their skepticism about including engineering in elementary classes (Cunningham, 2008). Similar mindsets about engineering and elementary engineering education were also found among the elementary teachers in previous research on EfF Summer Academies (Liu, Carr, \& Strobel, 2009). Given elementary teachers' unpreparedness for engineering teaching, it is reasonable to believe that there is much to be done by profession development providers to prepare elementary teachers for effective elementary engineering education.

What makes things harder for professional development providers is the fact that it is often difficult for teachers to translate knowledge gained through professional development in a way that meets their students' needs (Duffy, 2004; Gordon, 2004). This knowledge transfer problem is reflected in the common lore among teachers: teaching as happening in classrooms and "talk about teaching" as happening in universities are incommensurable. Professional development providers need to think about how to help teachers translate their professional development learning into effective teaching practices. The present study, by investigating how the elementary teachers in EfF Arlington, TX Summer Academy developed their PCK in engineering after finishing their 
professional development learning, was intended to offer some insight into how teacher professional development programs can be improved to better prepare elementary teachers for engineering teaching.

\section{METHODOLOGY}

A phenomenological research design was used to explore how engineering PCK was constructed the participating elementary teachers of EfF Arlington, TX Local Summer Academies. Data of this study were triangulated (Bogdan \& Biklen, 2007) through transcripts of the face-to-face individual and group interviews and the answers to the online open-ended survey questions. The interviews were transcribed and analyzed together with the answers to the open-ended survey questions.

\section{Participants}

The interviews of the study involved 73 elementary teachers (see Table 1 for demographic information of these teachers). While these 73 teachers interviewed signed up for the summer academies voluntarily, they were recruited into this study by a mix of convenience sampling and purposeful sampling. Out of the total 101 interviews, 76 were individual interviews (with 13 teachers interviewed both in 2008 and 2009) and 25 were group interviews.

Table 1: Demographic Information of the Teacher Participants

\begin{tabular}{|c|c|c|c|c|c|c|c|c|c|c|}
\hline \multirow{2}{*}{$\mathbf{N}$} & \multicolumn{2}{|c|}{ Gender } & \multicolumn{4}{|c|}{ Years of Teaching } & \multicolumn{4}{|c|}{ Grade Level } \\
\cline { 2 - 12 } & $\mathbf{F}$ & $\mathbf{M}$ & $\mathbf{0 - 2}$ & $\mathbf{3 - 5}$ & $\mathbf{6 - 1 0}$ & Over 11 & $\mathbf{2}$ & $\mathbf{3}$ & $\mathbf{4}$ & $\begin{array}{c}\text { Instructional Facilitator } \\
\text { (Across grades) }\end{array}$ \\
\hline 73 & 67 & 6 & 5 & 19 & 18 & 31 & 22 & 26 & 22 & 3 \\
\hline
\end{tabular}

The elementary teachers of this study came from 13 elementary schools in Arlington, TX teaching $2^{\text {nd }}$ grade through $4^{\text {th }}$ grade mostly in self-contained classrooms. Approximately half of the elementary teachers hold BA degree in fields such as English, early childhood education, interdisciplinary study, and government (See Figure 2). Twenty-eight out of twenty-nine BS degrees held by the teachers are in non-STEM fields like education, advertising, and photography. Nine of these teachers have Masters Degrees, three of which are in STEM-related fields (one in information processing technology and two in math education). One of the teachers has an EdD in curriculum and instruction with a focus on math education.

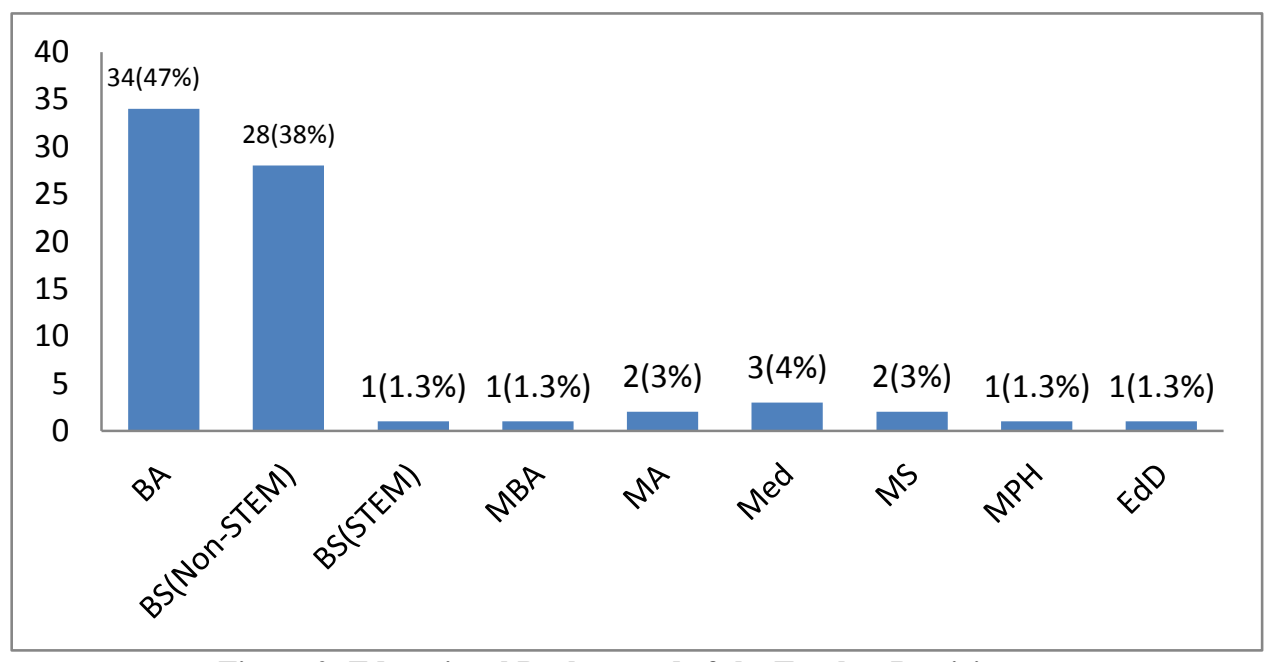

Figure 2: Educational Background of the Teacher Participants

Thirty-one elementary teachers responded to our online open ended survey about their beliefs, motivations, and concerns about integrating engineering activities into their classrooms. 
All participants of this study received one-week of training of elementary engineering teaching from EfF Arlington, TX Summer Academy aimed at helping elementary teachers enhance their understanding of engineering concepts and pedagogies through various EfF activities.

\section{Data Collection Procedures and Instruments}

A total number of 101 face-to-face interviews were conducted among the 73 teachers, including 76 individual interviews and 25 group interviews. The group interviews were conducted in June 2008, December 2008, and December 2009. The individual interviews took place in May 2009 and May 2010 respectively. The survey was posted online through SurveyMonkey in July 2009, and the survey data were collected in September 2009. The data were sorted in an Excel file after collection.

\section{Data Analysis}

This study included three sets of qualitative data: one from the group interviews, one from the individual interviews, and one from the answers to the open-ended online survey questions. According to the participating teachers' profiles, the individual interview transcripts were first divided into "Title I Schools" group and "Non-Title I Schools" group, and were then further divided according to the teachers' teaching experience into group 1 and group 5 of "0-2 years," group 2 and group 6 of "3-5 years," group 3 and group 7 of "6-10 years," and group 4 and group 8 of "over 11 years." While groups 1, 2, 3, and 4 belong to the "Title I Schools" group, groups 5, 6, 7, and 8 belong to the "Non-Title I Schools" group. Three interview transcripts were randomly selected from each of the eight groups.

The 24 individual interview transcripts and the answers from the open-end online surveys were first analyzed. The data analysis was guided by the ELC framework and the operational definition of engineering PCK of the study. Also, the principles of analytic induction (Bogdan \& Biklen, 2007) were adopted to help the researchers to build patterns of meaning from the data (Patton, 1990).

Specifically, three rounds of data analysis were carried out during the whole process. In the first round, the elementary teachers' responses to the online survey questions and the 24 interviews were read separately and independently by the researchers on a line-by-line basis. During the reading, the researchers took analytical memos about the patterns of difficulties and barriers perceived by the elementary teachers concerning integrating engineering into their classrooms. Comparing and discussing their analytical memos, the researchers reached an agreement on a list of themes with each theme overarching specific difficulty and barrier patterns emerged from the survey responses and the 24 interview transcripts.

In the second round of data analysis, each of the researchers read independently through the 24 interviews focusing on the specific engineering teaching strategies and methods the elementary teachers employed in their engineering instruction. While reading the interviews, the researchers took analytical memos about the patterns of how and why each of the instructional strategies and methods was used. Analyzing their analytical memos, each researcher came up with a list of themes and patterns. In this inductive process (Strauss \& Corbin, 1990), the original 24 interviews were reduced by each researcher into a list of themes, each of which captured and unified several patterns with corresponding instructional strategies and methods. Then, the researchers made comparisons across the themes and patterns they had respectively come up with and discussed the differences they had on the themes and patterns, referring back to the original interviews whenever necessary. Based on their discussion, the researchers modified the themes and patterns to better categorize and present the instructional strategies and methods. A final single list of themes and patterns resulted.

In the third round of data analysis, the researchers tested the two lists of themes and patterns from the first and the second round of data analyses against new interviews outside of the initial 24 interviews. Each time, each of the researchers randomly selected five transcripts from the individual interviews and five from the focus group interviews. While reading these new interviews, the researchers looked for new patterns not yet captured in the first and second rounds and either revised the existing themes or added new themes to reflect those newly emerged patterns. The testing process went on until no new patterns emerged, and the themes were saturated (Strauss \& Corbin, 1998). During the whole testing process, the two researchers met constantly and discussed their revisions of the themes and 
patterns to ensure the reliability and validity of the revisions. Two lists of core themes and patterns finally resulted: one on the difficulties and barriers of integrating engineering into elementary classrooms and one on the engineering instructional strategies and methods used by the elementary teachers in their engineering teaching practice. As the final step of the third round data analysis, the two researchers revisited the two lists of themes and patterns with reference to the ELC framework to interpret and make sense of the elementary teachers' construction of engineering PCK through engineering teaching practice.

\section{FINDINGS AND DISCUSSION}

In this study, the interview questions and the open-ended online survey questions were intended to allow the elementary teachers to articulate and reflect on their experiences, problems, and associated solutions about teaching engineering to their elementary students. We present our findings about the practice-based construction of engineering PCK based on the analysis and interpretation of these articulated experiences, problems, and solutions. Excerpts from the interviews and online survey answers were integrated to illustrate and support the findings presented.

\section{Learner Characteristics and Learning Difficulties: From Knowledge to Solutions}

The elementary teachers' engineering curriculum included four EiE lessons and a series of preparation activities to be done before and after the lessons. The preparation activities done before the lessons were: Active Listening, Teamwork, What's Engineering, What's Technology, Brainstorming about Technology, Critical Vocabulary, and Engineering Design Process. The Model Eliciting Activities were to be done after the EiE lessons. The elementary students in this study were second through fourth graders, representing an age group that is not typically exposed to engineering. Teaching engineering for the first time and teaching engineering to students of such an age group, the elementary teachers constructed their engineering PCK by gaining new knowledge about engineering teaching and learning difficulties and by producing specific engineering teaching strategies and methods to deal with these difficulties in their engineering teaching practice.

\section{Misconceptions about Engineering and Technology}

One prominent characteristic the elementary teachers noticed of their students was that the whole notion of engineering "is just very foreign to" their young students. The idea that "an engineer did a car" or "he works on a car" were firmly established in the elementary students" minds and even the "make vs. design" concept was hard for them to grasp. The elementary teachers tried giving textbook definitions like "an engineer is the person who designs, a craftsman is the person who makes it, and a technician is the person who uses it" and tried inculcating repeatedly to their students the ideas of "engineers don't always make it," "they design it" or "they're not always the one that puts it all together." But the elementary teachers realized that these just did not work. Then they tried something else. There were teachers who asked the students to "go home and talk with their family about 'What is engineering?" and "to get their family discussing it a little bit more, to find out if they had engineers in their family," so that the students "came up with a student-centered definition first" before the concepts of engineering and engineer were discussed in class. One of the elementary teachers did a mini unit on the inventors her students were interested in, and together, they looked at the inventors as engineers to see how they made life easier. There were also elementary teachers who invited to class engineers they knew or some students' parents who are engineers to talk to their students about what real engineers do.

When teaching about technology, the elementary teachers always began the "technology brainstorming" activity they learned in the EfF summer academy. As was reported by the elementary teachers, this activity was not effective in correcting their students' typical misconception that "technology was something that was robotic or required batteries." To help their students understand what technology truly is, some elementary teachers developed their own instructional methods. There were teachers who brought in simple tools like paper clips and nut crackers, and discussed with their students "what was the function," "what was the purpose," "what was the design," "how was it made," "what was it made of," and "how was it an improvement over previous inventions." Some elementary teachers adopted demonstration teaching methods to teach the concept of technology to their students. A good example was a $3^{\text {rd }}$ grade teacher who did the egg beater demonstration. According to this teacher, her students "tried the egg beater and saw how mechanically it was an improvement over the fork and how it made the job easier." There 
were also some elementary teachers who adopted more hands-on methods and strategies. One $4^{\text {th }}$ grade teacher brought in a little vacuum with automatic sensors. She picked the vacuum apart with her students and they talked about all the pieces in it. She also brought in bandaids and pencil sharpeners to allow her students to play with them and discuss in what ways they might be regarded similar to the vacuum.

The elementary students' misconceptions about technology and engineering unfolded to their teachers during the engineering learning and teaching process. In response to these misconceptions, the elementary teachers devised various strategies and methods to help their students correct these misconceptions. Though the strategies and methods were of different types, they were basically based on the understanding that "isolated mental pictures and images" or "abstract definitions" were not useful in teaching their students engineering and technology-related concepts. The elementary teachers learned from their engineering teaching practice that what their elementary students needed were "hands-on," "concrete and real-life examples," and "opportunities to think, to experience, and to improve" in order to understand technology and engineering-related concepts.

\section{Lacking Teamwork Abilities}

Engineering is a social endeavor requiring extensive teamwork. For successful implementation of an engineering lesson, as one of the elementary teachers mentioned in the interview, the elementary students' "being able to work together is the critical key." However, the elementary teachers learned from their engineering teaching experiences that their young students lacked "basic teamwork knowledge and abilities" for engineering activities, especially for those design activities requiring teamwork for designing and producing a final product. The elementary teachers tried some methods they used in teaching other disciplines. They tried putting students with more leadership quality with those with less or they grouped their students according to friends-with-friends principle or the principle of putting in a group those who could get along together. However, those methods that worked well in activities of other disciplines failed to work in engineering design activities. The engineering design activities usually involved solution finding, decision making on design solution, and cooperation in producing and improving the final design product. Elementary teachers were able to see that, in such a complicated process, it was hard for their young students to get along. "A lot of arguments" and "my idea is the only idea or I don't want to do what you want to do" were reported as common among the elementary students in the engineering design activities.

To enable their students to work better in those engineering design activities, the elementary teachers developed different methods and applied these methods to their engineering teaching. Some of them adopted the visual modeling method by which they used Aisha story DVD or PBS shows like Design Squad to model engineering teamwork for their students. Some elementary teachers used the team-building method of creating flow maps and putting down important things for working as a team in engineering design activities, such as "how to work cohesively together," "be open to new ideas and things," "making contribution as team member," and "be responsible and respectful." They discussed with their students these important concepts, and referred the students back to those important concepts when the engineering design activities were on-going. There were also elementary teachers who used a role-playing method for teamwork. Using this method, the elementary teachers assigned each team member a role, such as lead engineer, material handler or material manager, and facilitator, and defined and put down each role's function and responsibilities before carrying out the engineering design activities with the elementary students.

In their engineering teaching practice, the elementary teachers realized their students' inadequate teamwork abilities for engineering design activities. Instead of grouping the students into small groups and starting doing those activities or following those methods that worked for group activities in other disciplines, many elementary teachers created their own methods for eliciting better learning results from their students. These newly-created methods were strong evidence that teachers were "learning in and from practice" (Ball \& Cohen, 1999) about how to cultivate their students' engineering teamwork skills and how to make engineering design activities workable and doable for elementary students. For the elementary teachers, this was a process from knowing about their students' lack of teamwork abilities to knowing how to deal with it in the engineering teaching practice.

Learning Difficulties

For the elementary teachers, teaching engineering to elementary students was a process of discovering their engineering-associated learning difficulties. Some difficulties were related to the fact that some engineering lessons 
and activities required mastery of some skills or concepts the elementary students had not yet mastered, such as measurement, fractions, and the concept of variables. As reported by the elementary teachers, their students "had a difficult time with measurement in the folder-making activity, like measuring one-fourth of an inch, they "couldn't get the fact that the measurement had to be exact," they "just didn't understand that when the bottom number gets bigger, that means it's smaller," or in the Play-Doh activity they "didn't know one can only change one variable to actually figure out what's working." Some elementary teachers modified the engineering activity to make the measurement less difficult, brought in measuring cups to teach their students about fractions, or used flour and salt to demonstrate the concept of variables.

These learning difficulties informed the elementary teachers about what needed to be done to ensure those engineering lessons and activities were doable for and teachable to their students. More important than this was that these learning difficulties allowed the elementary teachers to see that engineering teaching and learning "was not isolated from the learning and teaching of other disciplines" and there were "many cross-curricular connections that could be made between engineering and other disciplines." For some elementary teachers, these understandings served as a starting point for their search of how to combine engineering with the teaching and learning of other disciplines they had been teaching. For some elementary teachers, the section in their social studies book about assembly lines became a good place where the teaching of the "assembly line process" was able to be tied in. While one elementary teacher extended her science lesson on filter into a filter design activity, another teacher "did a unit on the engineering design process to design and improve a telescope" after her lessons on solar system to show her students "how it is possible to see the solar system without traveling through space."

Some elementary teachers even brought engineering into their teaching of language arts. One elementary teacher elaborated, during the interview, on how she integrated the pop-up card activity with the author-study activity on William Steig in language arts. Her students worked in groups doing research on William Steig's books, "chose their own books from William Steig's collection," "chose their characters and elements of the story," "made all the drawings," and presented them on the pop-up cards they designed. This teacher understood "the key points of the engineering ideas and precepts as exploration and coming up with one's own independent thinking." So she did not impose on her students "any constraints whatsoever with how they were to do it [the pop-up cards: note by the authors]" and "did not give them any instructions on actually how to assemble it and design it themselves." But she did tell her students to make their pop-up cards more animated and exciting to look at, "not just a flat two dimensional drawing." This, to use the teacher's own words, "brought in the math component as well" into the pop-up cards activity.

When this teacher reflected on this activity, she said only two groups were very successful with their pop-up cards and the quality of the work of other groups was not good. But she mentioned in her interview that "even now, several months after having done the pop-up cards, my kids are on their own, finding their own way of improving their little pop-up cards, to make sure they work better and things work nicer." This, according to the teacher, was what really mattered. She understood from her engineering teaching experiences that teaching engineering in isolation sometimes interfered with the "flow of the teaching and learning of other disciplines" and undermined students' ability to see the connections between engineering and other disciplines. However, integrating engineering into the learning of other disciplines not only made the learning of other disciplines much more fun but it also allowed the students to see relevant applications of engineering. This was regarded by this elementary teacher as a motivating force for her students' continuous work on the improvement of their pop-up cards.

Another engineering learning difficulty the elementary teachers found common among their students was related to the engineering design process. The design process the elementary teachers introduced to their students was the EiE engineering design process (Cunningham, 2009; Hester \& Cunningham, 2007), which included five phases (see Figure 3) forming a continuous circle around the design goal. 


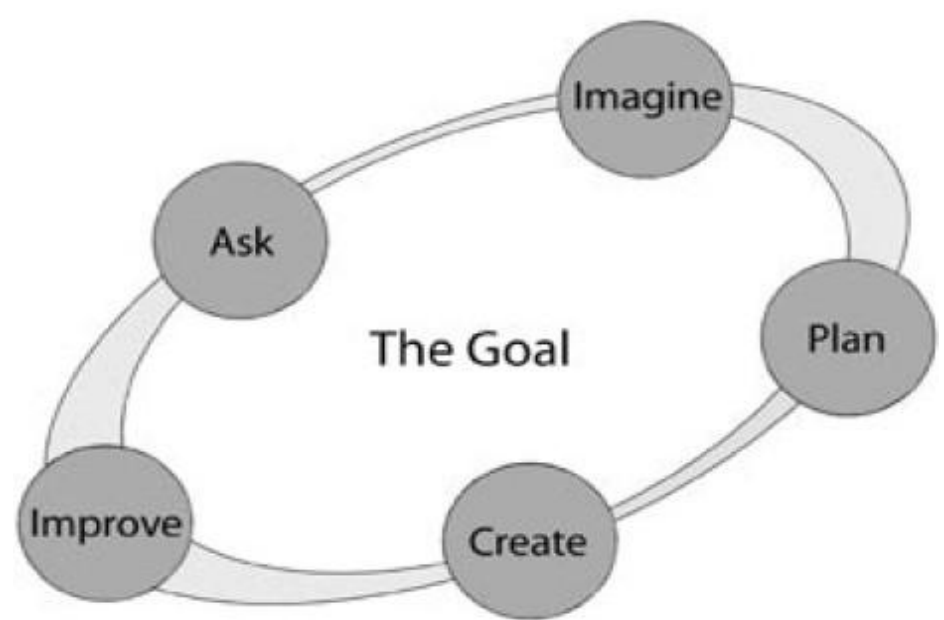

Figure 3: The EiE Engineering Design Process (Adapted from Cunningham, 2009)

As was reported by the elementary teachers, the engineering design process, like the engineering concept, was very foreign to the elementary students. Showing the students the process graph or making a bulletin board with the steps, and explaining what would happen at each step was the initial method used by many elementary teachers to introduce the engineering design process to their students. But this method in most cases only resulted in memorization of a few steps by a few students. In addition to their confusions about the steps, the elementary students kept asking question like "Is this important?" or "Why are we doing this?" The elementary teachers felt the need for an alternative method of teaching the design process. Many analogies arose as a result. Relying on their students' prior knowledge about the writing process and the scientific process, some elementary teachers compared and contrasted the writing and scientific processes with the engineering design process to allow their students to build a working model of the engineering design process. Such analogies achieved better learning effects on the students: while they were doing their writing, they would see "That kinda goes with the planning process," or when they were doing their science experiments, they would see something similar to the engineering design process involved like "We need to test it, and if it doesn't work, we're going to need to improve it."

For some elementary teachers, the best way to teach the engineering design process was through the "learning by doing" strategy. They either asked their students to work in groups or work as a class to brainstorm what they planned to do in each of the engineering design steps and create flow maps guiding their design and creation of the design products like paper tables and paper folders. The students referred back to their flow maps while designing and creating their products and reflected on the flow maps about the functions of the design process and what worked well and what did not. Some elementary teachers improved this "learning by doing" strategy by asking their students to design and create things they were interested in. Instead of doing the engineering design activities they brought back from the EfF summer academies, these elementary teachers created such engineering design activities as "a bed for your doll," "a chair for my mother," and "a house for the three little pigs." The teacher, who asked her students to build the house for the little pigs, recalled how her students manipulated with different materials, like marshmallows, craft sticks, and paper clips, and how much they were engaged in testing their houses with hair dryers or fans and in improving their houses based on the tests.

The elementary teachers developed their knowing about their students' engineering learning difficulties through their engineering teaching practice. Again, knowing about these difficulties did not automatically result in the elementary teachers' knowing of how to deal with them. Those strategies or methods used to help the students overcome their learning difficulties were developed by the elementary teachers as a result of their trying-and-then-understanding about what would work better for their students in engineering lessons or activities.

\section{Engineering Learning Assessment}

Assessing student learning is what every teacher has to do. One of the elementary teachers said that in engineering teaching "the hardest thing for me is the assessment." This was also the case for many elementary 
teachers. The teaching materials the elementary teachers received from the EfE summer academy contained questions, rubrics, and assessments instruments that were intended to be used by the elementary teachers to assess their students' engineering learning. However, after trying these ready-made assessment tools, some elementary teachers realized that some formal assessment methods or tools applicable to other disciplines like math and language arts were not readily workable for assessing their students' engineering learning. Three main reasons, as reported by the elementary teachers, stood behind their practice-derived perception of the need for some informal assessment methods. First, young students at the age of $2^{\text {nd }}-4^{\text {th }}$ grade levels became stressed out easily by formal assessment or tests, and it was especially the case when they were facing a discipline like engineering which was very foreign to them. Second, it took more time for the elementary students to master those unfamiliar engineering-related concepts, so informal formative assessment would be desirable to ensure better learning outcomes. Third, there were wide spread and high level frustrations among the elementary students resulting from unsuccessful production of final engineering design products, and this called for assessment methods that could "turn the frustrations around" and could help develop the students" "ability to go back, re-create, and improve."

Based on the practical learning situations of their students, the elementary teachers employed different informal assessment methods in their engineering teaching. Some assessed their students by "doing a lot of questioning" and some checked their students' understanding by looking at the examples of simple machines or technology they found in their houses. There were also some elementary teachers who got to know their students' learning needs through things they wrote down in their notebooks or journals, by observing, listening, and talking to them, or based on the students' feedback about how they perceived and how they were able to make sense of those engineering concepts and activities. In those engineering design activities, "focusing on the exploration process not the final products" was a common feature of the informal assessment methods used by the elementary teachers. Some of the elementary teachers assessed their students' design products by having them talk about why or why not they thought someone would want to buy their products, or about what "limitations and time or material constraints" had contributed to their failure of "getting their job finished." One of the elementary teachers worked with her students to create flow maps of recipes and according the teacher, "a recipe is steps to make something." She assessed her students based on their recipe maps, posing questions like "Did you follow the flow map you wrote?" and "You didn't follow your flow map. Did you have any problems?" Some elementary teachers invited a group of parents or kindergarteners to their classrooms as the "consumer-group" giving the students feedback on their design, and the students re-designed their products based on the feedback.

Some elementary teachers even asked their students to come up with their own criteria for assessing their engineering design products. One elementary teacher's students decided to test their paper tables by seeing which groups" table "could stack the most books" and one group said, "Well, we need to weigh their books. They may not be as heavy as our books." Another elementary teacher talked about the creative testing methods her students used to test the quality of their play-doh such as the "stick to hands or desk test" and "the stamp test" of pressing erasers of various shapes down into the play-doh to see if it "kept the shape or closed back." According to these teachers, having their students come up with their own criteria for testing their products would allow their students to have a clear picture about the goal of their design from the very beginning and would enable the students to focus on what needed to work on for improvement to reach the goal rather than being overwhelmed by possible frustrations associated with failure to reach the goal.

We were able to see that the assessment difficulties the elementary teachers encountered in their engineering teaching practice were closely related to their students' engineering learning difficulties. The assessment choices and decisions the elementary teachers made were based on their understanding of student learning difficulties and of ways to better meet student learning needs in engineering learning situations. And more importantly, these choices and decisions were based on their trials of what worked and what did not for their students in engineering learning situations. In search for assessment methods that worked for their students, the elementary teachers were constructing their situated knowledge about assessing engineering learning and about encouraging and improving engineering learning by assessing their students appropriately.

\section{Contextual Constraints: From Knowing-About to Knowing-How}

Teaching, like learning, happens in specific contexts. The elementary teachers in this study had no prior engineering teaching experiences in real classroom and real school settings. Their knowledge about the contexts of 
elementary engineering teaching came to them after they left EfE summer academy to start their engineering teaching practice in their own elementary classrooms. Their knowledge of contexts included knowledge about the classroom contexts and about the school contexts and about how these contexts influenced their engineering teaching practice.

\section{Classroom-Related Contextual Constraints}

Elementary classrooms were the immediate contexts within which the elementary teachers had to work to carry out their engineering instruction. The elementary teachers' knowledge about classroom contexts unfolded to them in the form of a series of classroom-related contextual constraints that rendered negative impact on engineering instruction. A list of these classroom-related contextual constraints were identified from the interviews with the elementary teachers:

\section{- $\quad$ Large class size but with no assistant \\ - $\quad$ Discipline issues \\ - $\quad$ High student turnover rate \\ - Learner diversity}

In the teaching of non-engineering disciplines, the above classroom-related contextual constraints are also unavoidable. Although none of these contextual constraints were unique to engineering teaching, all of them made an impact on the elementary teachers' engineering teaching. As was reported by many elementary teachers, the large size of their class and the discipline issues with some of their students held them back in their engineering teaching and made it very difficult to plan the engineering group projects. For those elementary teachers who had "very transient student population," they had to forgo some engineering activities because of "frequent turnover" and "high transient rate" of their students.

The contextual constraints related to "learner diversity" manifested themselves in different ways for different elementary teachers. For some elementary teachers, this constraint was related to the diverse academic abilities among their students. For these teachers, their elementary students in a single class ranged from those of "straight A" to those who had to copy all stuff from others, from those mature to those extremely immature and having "just recently stopped crying," or from those good at critical thinking to those have "no critical thinking skills whatsoever." For many other elementary teachers, the "learner diversity" constraint was associated with their student body which consisted of both native-English-speaking students and a large number of ESL students, who were diverse in their language and academic abilities.

Despite the fact that the meanings of "learner diversity" were teacher-dependent, the elementary teachers found it always a big challenge to strike a balance between the diverse learning needs of their students during their engineering teaching practice. Sometimes they had to modify their engineering teaching by "cutting steps," "cutting directions," "rewording everything," and "making it simpler and playful." These modifications were intended, as one of the teachers put it, to ensure those students at the lower end of the continuum to "at least be able to take something away" from their engineering learning. Some of the elementary teachers talked about "how important dialogue was" and used a lot of conversations to prepare their less capable students for the engineering lessons.

In their engineering teaching practice, the elementary teachers became acquainted with those classroom related contextual constraints and had to adopt specific instructional measures to counteract the negative impact of these contextual constraints. Not uniquely specific to engineering teaching, these contextual constraints and instructional measures were generic in nature. However, knowledge about these contextual constraints and how to deal with them appropriately is definitely a valuable part of the elementary teachers' understanding about elementary engineering education. More importantly, since most of these contextual constraints offered different perspectives allowing the elementary teachers to see the engineering learning difficulties of their students, knowledge about these contextual constraints and how to deal with them would contribute to the elementary teachers' abilities of making engineering content teachable. 


\section{School-Related Contextual Constraints}

Analysis of the results of the online survey from the elementary teachers revealed the difficulties and barriers they perceived concerning integrating engineering into their classrooms:

- $\quad$ Time issue (Lack of time for engineering teaching)

- $\quad$ Lack of administrative support

- $\quad$ Accountability issues (e.g., state-mandated tests, meeting standards, and instructional objectives)

- $\quad$ Personal unpreparedness (e.g., lack of engineering content knowledge, unfamiliarity with engineering design process, and lack of engineering teaching experience)

- $\quad$ Student-related issues (e.g., age-appropriateness, academic preparedness, and learning interests)

The first three in the list corresponded with the school related contextual constraints perceived by the elementary teacher in their engineering teaching practice. Engineering was not a discipline the elementary teachers were required to teach. Integrating engineering into their classrooms meant that they had to find time for engineering from their already packed teaching schedule. This was not easy for these elementary teachers because most of them taught in self-contained classrooms and were responsible for teaching all subjects to their students. One of the elementary teachers said in her interview that "my curriculum sadly consists of a lot of teaching, testing, and re-teaching of specific objectives in those subject areas. I have TEKS [Texas Essential Knowledge and Skills: note by the authors] for every subject area including Computer Science. I have to learn how to balance and incorporate it all." Similar things were mentioned by another elementary teacher: "We have not only academic things that we are responsible for as far as testing is concerned, but wherever there are learning gaps with our students, we are then commended with closing those gaps; and the bigger the gap is, the more intensive and the more time that we are forced to spend with a student outside of our regular teaching time. So I think it's a really hard balance to try to make." What these two teachers said was the typical situation most elementary teachers in this study were in and the "time issues" were therefore perceived by them as the biggest barrier to integrating engineering into their classrooms. Also, it was not hard to see that the "time issues" were inseparable from what they were held accountable for as elementary teachers.

These time and accountability issues had great impact on the elementary teachers' engineering teaching practice. Many elementary teachers reported in the interviews that they found it hard for them to carry out engineering teaching on regular basis. They sometimes had to leave engineering aside to prepare their students for the benchmarks, the TAKS, or the end-of-year testing and it was not uncommon when some of the elementary teachers picked up engineering where they left off last time, their students had long forgotten what had been covered. Knowing about these time and accountability issues and the constraints these issues set upon their engineering teaching, some elementary teachers began to search for ways that would help fight against these constraints. One good example of this came from one elementary teacher who did the "The Great Egg Drop" activity with her students.

Instead of doing the EiE Packaging Plants activity which was totally new for her students, the elementary teacher did the "The Great Egg Drop" activity which involved packaging design for raw eggs to protect the eggs in a six-foot drop. She had done this activity with her students before she attended the EfF summer academy and the students had been asked to design their packages at home and tested them at the school. She modified the activity and did it in a new way:

"The way I did it this year was, rather than have them package it at home, I let them go home and gather materials; I told them the constraints... Then they went home and they had a specific date they had to bring materials back... So anyway, they had their materials, they built their package here. Before doing that, though, they had to sketch what they wanted their package to look like and diagram it. Then they wrote a procedure down of how they put their packaging together and how the egg was going to be secure, and then we took it outside and did a six-foot drop. I let them come back in, if their egg didn't make it, they had to improve their package, and then we took it to the roof. After that, they wrote up their findings." 
According to this teacher, it was time-efficient to adapt such a science activity in physics with which her students had prior experience with into an engineering design activity. Since there was no need to prepare the students from scratch for what they were to do, the students would be able to have a more focused experience with the engineering design process and to accomplish more in less time.

Different from this "more with less time" strategy was the strategy adopted by a $4^{\text {th }}$ grade teacher. Since electricity and magnetism are in the $4^{\text {th }}$ grade TAKS, this $4^{\text {th }}$ grade teacher created a "circuit design" engineering activity and combined this activity with her teaching of electricity and magnetism. This teacher's "test-alignment" strategy was based on her belief that "if you would align with what you had to do versus trying to wiggle room for it, that would be helpful." There was another teacher who also adopted this "test-alignment" strategy. But she used this strategy in a different way. Instead of creating some engineering activities that were in alignment with the TAKS, she used the engineering teaching materials preparing her students for the TAKS. For example, she used the engineering stories to prepare their students for TAKS language arts and TAKS social studies. As this teacher said, "the Texas Essential Knowledge and Skills are in the stories, so you can practice: Who are the main characters? What are their feelings? What's the setting?... I didn't mind that it took me two extra days to do the activities. I did not cover all the social studies in that six weeks that I was supposed to cover. But I didn't feel like I didn't get my practice for the TAKS test with it."

In addition to those contextual constraints associated with time and accountability issues, the elementary teachers voiced in the interviews the issues related to lacking administrative support they perceived in their engineering teaching practice. According to the elementary teachers, engineering teaching "still sounds appended to the main business of school" because "it's not state mandated," "it's not included in the TAKS tests," and "the EiE stuff doesn't look at all like the state tests." One of the elementary teachers talked about the lack of support from administration and board members. Her comments were a good summary of the status quo of administrative attitudes toward elementary engineering integration as perceived by many other teachers:

There is a push to concentrate on 'teaching to the test.' There is a very strong insistence to worry about test scores and not developing the whole student. I am afraid that I may be told to cut back on this area of instruction. [engineering instruction: note by the authors]

To realize integration of engineering into elementary classrooms, as one of the elementary teachers commented, "The whole school would have to get onboard. It would take a whole-school push, starting with the principal, and the principal would have to really mandate it, and be willing to manage it and revisit it and visit it in the classrooms and expect to see it in the classrooms." Some of the elementary teachers talked about the need to get buy-in not from the principals but from other teachers in their schools and the parents by allowing them to "see the payoffs." Some suggested holding "Engineering Open House" to "have the kids showing what they've learned." There were also teachers who thought it would be a neat idea to publicize what they were doing about engineering in their classrooms through TV or the internet. According to them, this would be a great educational push for integrating engineering into elementary classrooms. One of the teachers took pictures of her students when they were working on the engineering power station activity and put the pictures on the school district web page. As she said, "the first thing you see are those pictures that pop up."

The above plans and thoughts from the elementary teachers were intended to improve the school environment so as to make it more conducive for engineering integration. These plans and thoughts were evidence that the elementary teachers gleaned from their engineering teaching practice knowledge about those school contexts constraining elementary engineering education. Such knowledge would provide the elementary teacher with valuable guidance of how to adapting their engineering teaching practices to the contextual constraints to ensure more successful and sustainable integration of engineering into their classrooms.

\section{Discussion}

The findings of this study revealed that the elementary teachers developed two types of knowledge through their engineering teaching practice: 1) Knowledge about engineering teaching and learning difficulties and various classroom- and school-related contextual constraints on elementary engineering integration; 2) Knowledge about 
engineering teaching strategies and methods dealing with the above difficulties and contextual constraints. These two types of knowledge covered both the " $\mathrm{L}$ " dimension and the "C" dimension in the ELC framework of this study, but they were of quite different nature. Based on their review of previous literature, Mason and Spence (1999) distinguished two types of knowledge: knowing-about which includes "knowing-that (factual), knowing-how (technique and skill), and knowing-why (having a story in order to structure actions) (p. 135)" and knowing-to which is the active knowledge that enables one to act and respond to specific new situations. Of the two aforementioned types of knowledge the elementary teachers developed through their engineering teaching practice, the former one would be classified as knowing-about while the latter as knowing-to. And the elementary teachers' knowing-to was the engineering PCK as defined in this study.

According to Mason and Spence (1999), knowing-about, albeit important, is not sufficient to enable teachers to handle particular learning and teaching situations. To be able to do so, teachers need to develop their knowing-to. But knowing-about does not necessarily entail the development of knowing-to. The elementary teachers started their engineering teaching practice with existing knowing-about. Such knowing-about included the "knowing-that," "knowing-how," and "knowing-why" they accumulated from their prior experience in teaching non-engineering disciplines and also included the "knowing-that," "knowing-how," and "knowing-why" they learned through the training in the EfF summer academy. In their engineering teaching practice, they developed their knowing-about of engineering teaching and learning difficulties and various classroom- and school-related contextual constraints. Does this newly developed knowing-about together with their pre-existing knowing-about automatically allow them to know how to act and respond to the specific engineering learning situations in their classrooms?

The inert knowledge problem prevents us from applying existing knowledge to new situations (Gambro \& Switzky, 1996; Mandl, Gruber, \& Renkle, 1994; Miller \& Gildea, 1987; Renkl, Mandl, \& Gruber, 1996). This inert knowledge problem may help explain the knowledge transfer problem in professional development and the common lore among teachers that were mentioned earlier in this paper. Of the three types of explanations (i.e., metaprocess explanations, structure deficit explanations, and situatedness explanations) identified by Renkl et al. (1996) for the causes of the inert knowledge problem, situatedness explanations are based on the perspective that "knowledge is fundamentally situated and, therefore, context-bound" (p. 115) and attribute the causes of the inert knowledge problem to the differences between new situations and previous situations from which prior knowledge was built. Teachers' knowledge about teaching is deeply situated in classroom practices (Shulman, 1987) and is deeply dependent on particular times, places, and contexts (Orton, 1993). The elementary teachers in this study had no prior engineering teaching experience before participating in this study and engineering was a discipline seldom taught at the elementary level. So, the new engineering teaching and learning situations would possibly render the elementary teachers' knowing-about, whether pre-existing or newly-acquired, inert and consequently made them unable to deal with the new engineering teaching and learning situations. However, the knowing-to the elementary teachers developed through their engineering teaching practice provided strong evidence that this was not the case.

Findings from this study revealed those "trials and failures" the elementary teachers experienced before they arrived at their knowing-to. In face of the teaching and learning difficulties and contextual constraints encountered in their engineering teaching practice, the elementary teachers tried the instructional strategies and methods which they used and were effective in teaching other non-engineering disciplines but found these strategies and methods did not work for the engineering learning situations at hand. The elementary teachers initially carried out the engineering lessons and activities as they had learned in the EfF summer academy but later realized that these lessons and activities needed to be done differently to make engineering teaching workable under the contextual constraints. Such trials and failures allowed the elementary teachers to see what did not work for their students in the new elementary engineering teaching contexts, which finally led the teachers to become successful in finding the teaching strategies and methods that worked. This "trial-failure-success" process empowered and situated the elementary teachers' knowing-about, turning it into knowing-to that were responsive to particular engineering learning needs and engineering teaching contexts.

Describing themselves as "radical constructivists," Cochran et al. (1993) adopted the term PCKg (Pedagogical Content Knowing) to refer to PCK based on the belief that the word "knowledge" is too static to capture the dynamic process where teachers construct their PCK. Findings from this study presented an engineering PCK development process (illustrated in Figure 4) which is not only dynamic but evolving. During this process, the 
elementary teachers first developed their knowing about engineering teaching and learning difficulties and classroomand school-related contextual constraints. And then they engaged themselves in a trial-failure-success process which empowered and situated their newly-developed and pre-existing knowing about. It was in this process that the elementary teachers constructed their engineering PCK or knowing-to in the form of instructional strategies and methods overcoming those difficulties and constraints uncovered by their knowing-about.

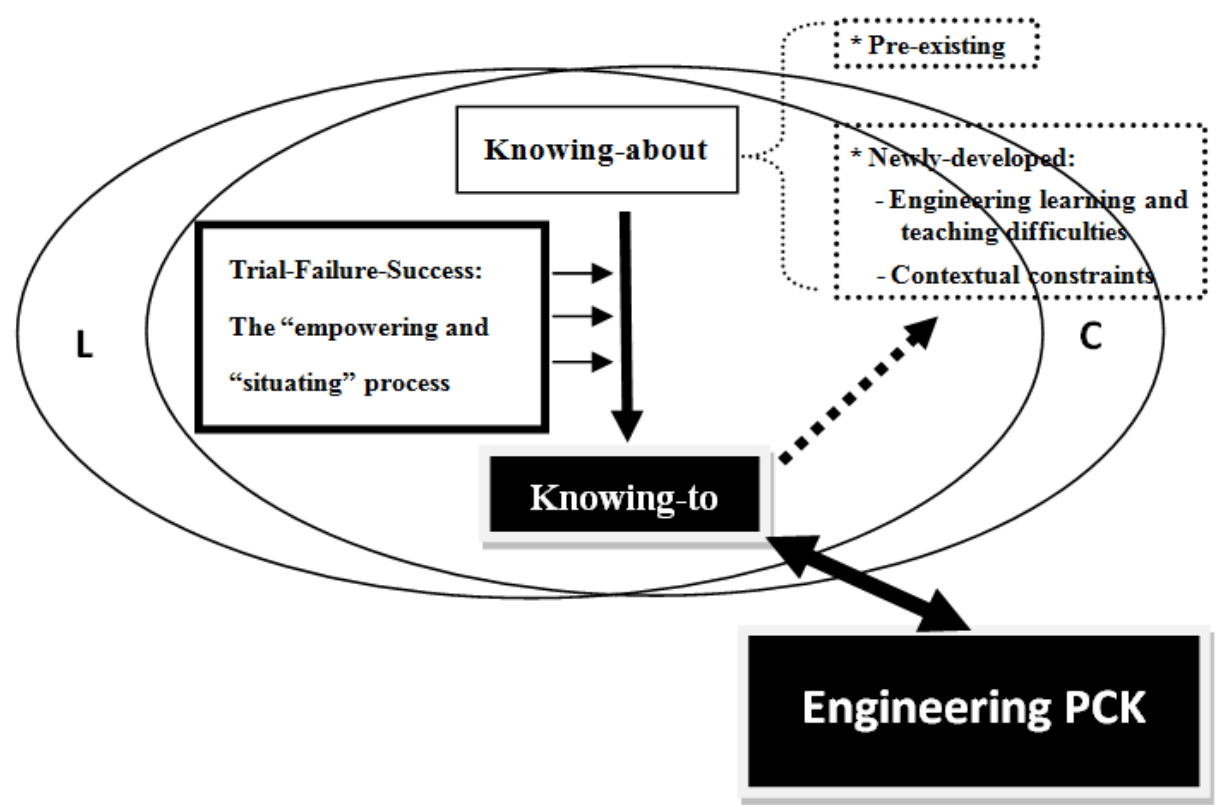

Figure 4: Engineering PCK Development

\section{CONCLUSION AND IMPLICATIONS}

The elementary teachers in this study received one week of EfF engineering teaching training and were provided with engineering curriculum and teaching materials to be used for classroom implementation. The EfF training, their prior non-engineering teaching experience, and their newly developed knowledge about engineering teaching and learning difficulties and contextual constraints served as knowing-about based on which the elementary teachers constructed their engineering PCK. However, indispensible for their constructing of engineering PCK was the trial-failure-success process the elementary teachers engaged themselves in during their engineering teaching practice. This dynamic process was a sense-making process empowering and situating the elementary teachers' knowing-about and transforming their knowing-about into engineering PCK.

The importance of this sense-making process carries valuable messages to professional development programs: 1) Elementary teachers' engineering PCK development should be approached from a dynamic and evolving stance rather than a possessive and static one; 2) The sense-making process rooted in real classroom and school settings is essential for elementary teachers' construction of engineering PCK; 3) Absence of this sense-making process may result in the inertia of elementary teachers' knowing-about and consequently block elementary teachers from responding effectively to student engineering learning needs and contextual constraints.

The elementary teachers' situated and practice-based knowing-about and knowing-to concerning engineering teaching in elementary classrooms are valuable resources that can be used for the improvement of future EfF elementary engineering training programs. The findings of the study suggest that a "returning, sharing, and improving" mechanism can be adopted by EfF and other similar professional development programs to improve engineering professional development for both in-service and pre-service elementary teachers. The mechanism can work like this: Invite previous teacher learners who have practiced engineering teaching in real elementary classrooms to return and share their knowing-about and knowing-to with new participating teachers. This will help new teacher learners enrich their knowing about engineering teaching and learning, facilitate their sense-making process, and promote their engineering PCK construction once they leave professional development programs to start their engineering teaching 
practice. Professional development faculty and organizers can improve instruction and training materials for their future participating elementary teachers based on the knowing-about and knowing-to gathered from their previous teacher learners.

The knowing-about and the knowing-to related to the "contexts" dimension would be especially important for professional development programs if they aim to permeate engineering into elementary classrooms. The knowing-about and the knowing-to related to the "contexts" dimension, for example, would help professional development programs to ensure that the elementary engineering lessons or activities they develop are aligning with what elementary teachers have to do as mandated by state or school curriculum. The "kill-two-birds-with-one-stone" effects achieved through such engineering lessons or activities will definitely promote the permeation of engineering into elementary classroom.

The permeation of engineering into elementary classrooms also relies on including pre-service teachers into professional development of engineering education. The "returning, sharing, and improving" sessions would be helpful to pre-service teachers as well. Those sessions can facilitate their future development of engineering PCK and can prepare them for possible difficulties and issues they may encounter in their future elementary engineering teaching practice.

\section{ACKNOWLEDGEMENTS}

This work was made possible by a grant from the National Science Foundation (DLR 0822261). Any opinions, findings, and conclusions or recommendations expressed in this material are those of the authors and do not necessarily reflect the views of the National Science Foundation.

\section{AUTHOR INFORMATION}

Dr. Yan Sun is currently a Postdoctoral researcher at Texas A\&M University and will start as an Assistant Professor of Instructional Technology at the University of West Alabama in August, 2014. She received her Ph.D. in Learning, Design, and Technology from Purdue University. Her research and teaching focus on integrating emerging technologies into K-12 teaching, improving K-12 teachers' knowledge and skills for technology integration, models and frameworks for guiding and assessing K-12 teachers' technology integration practices, preparing elementary teachers for elementary engineering education, and improving K-12 math and science learning through engineering integration.

Dr. Johannes Strobel is the Director of Educational Outreach Programs and an Associate Professor of Engineering \& Education at Texas A\&M, College Station. He received his M.Ed. and Ph.D. in Information Science \& Learning Technologies from the University of Missouri. His research/teaching focuses on engineering as an innovation in pK-12 education, policy of STEM education, how to support teachers and students' academic achievements through engineering, engineering 'habits of mind' and empathy and care in engineering. He has published more than 100 journal articles and proceedings in engineering education and educational technology and is the inaugural editor for the Journal of Pre-College Engineering Education Research. E-mail: jstrobel@ tamu.edu (Corresponding author)

\section{REFERENCES}

1. ACT. (2006). Developing the STEM education pipeline. Iowa City, IA: ACT.

2. American Association of State Colleges and Universities. (2005). Strengthening the science and mathematics pipeline for a better America. Policy Matters, 2(11). Retrieved from http://www.congressweb.com/aascu/ docfiles/v2n11.pdf.

3. Ball, D. L., \& Cohen, D. K. (1999). Developing practice, developing practitioners: Toward a practice-based theory of professional education. In L. Darling-Hammond \& G. Sykes (Eds.), Teaching as the learning profession: Handbook of policy and practice. (pp. 3-32). San Francisco: Jossey-Bass.

4. Ball, D. L., Thames, M. H., \& Phelps, G. (2008). Content knowledge for teaching: What makes it special? Journal of Teacher Education, 59(5), 389-407. 
5. Banks, F., Leach, J., \& Moon, B. (2005). Extract from 'new understandings of teachers' pedagogic knowledge'. Curriculum Journal, 16(3), 331-340.

6. Barnet, J., \& Hodson, D. (2001). Pedagogical content knowledge: Toward a fuller understanding of what good science teachers know. Science Education, 85, 426-453.

7. Barnett, J. (1999). PCxK: A synthesised model of exemplary science teachers'knowledge. Paper presented at the annual conference of the Australasian Science Education Research Association, Rotorua, New Zealand.

8. Bogdan, R., \& Biklen, S. (2007). Qualitative research for education: An introduction to theory and methods. Boston: Allyn \& Bacon.

9. Buczynski, S., \& Hansen, C. B. (2010). Impact of professional development on teacher practice: Uncovering connections. Teaching and Teacher Education, 26, 599-607.

10. Business Roundtable. (2005). Tapping America's potential: The education for innovation initiative. Washington DC: Business Roundtable.

11. Carson, R., \& Campbell, P. B. (2007). Engineering is elementary, exploring the impact of EiE on participating teachers. Massachusetts: Campbell-Kibler Associates, Inc.

12. Cochran, K. F., King, R. A., \& DeRouiter, J. A. (1993). Pedagogical content knowledge: A tentative model for teacher preparation. Paper presented at the Annual Meeting of the American Educational Research Association, Chicago, IL.

13. Cunningham, C. (2008). Elementary teacher professional development in engineering: Lessons learning from Engineering is Elementary. Engineering is Elementary, The National Center for Technological Literacy, Museum of Science, Boston. Retrieved from http://www.mos.org/eie/pdf/research/asee_2008_lessons_ learned.pdf

14. Cunningham, C. M. (2009). Engineering is Elementary. The Bridge, 30(3), 11-17.

15. Cunningham, C. M. \& Lachapelle, C. (2010). The impact of Engineering is Elementary (EiE) on students' attitudes toward engineering and science. Engineering is Elementary, The National Center for Technological Literacy, Museum of Science, Boston. Retrieved from http://www.mos.org/eie/pdf/research/ ASEE_Attitudes_paper_2010_final.pdf

16. Cunningham C. M., Lachapelle C., \& Keenan K. (2010). Engineering is Elementary, Elementary teachers' changing ideas about STEM and STEM pedagogy through interaction with a pedagogical-supportive STEM curriculum. The National Center for Technological Literacy, Museum of Science, Boston. Retrieved from http://www.mos.org/eie/pdf/research/Cunningham_R1362.pdf

17. Duffy, F. M. (2004). Moving upward together: Creating strategic alignment to sustain systemic school improvement. Lanham, MD: Scarecrow Education.

18. Faux, R. (2006). Evaluation of the MOS PCET Program, Interim Report. Boston, MA.

19. Fernández-Balboa, J. M., \& Stiehl, J. (1995). The generic nature of pedagogical content knowledge among college professors. Teaching and Teacher Education, 11(3), 293-306.

20. Gambro, J. S., \& Switzky, H. N. (1996). A national survey of high school students' environmental knowledge. The Journal of Environmental Education, 27(3), 28-33.

21. Gordon, S. P. (2004). Professional development for school improvement: Empowering Learning Communities. New York: Pearson.

22. Grossman, P. (1990). The making of a teacher. New York: Teachers College Press.

23. Hester, K., \& Cunningham, C. (2007). Engineering is Elementary: An engineering and technology curriculum for children. Paper presented at American Society for Engineering Education 2007 Annual Conference.

24. Jimoyiannis, A. (2010). Designing and implementing an integrated technological pedagogical science knowledge framework for science teachers professional development. Computer and Education, 55, 1259-1269.

25. Jobs for the Future. (2007). The STEM workforce challenge: The role of the public workforce system in a national solution for a competitive science, technology, engineering, and mathematics (STEM) workforce. Washington, DC: Employment and Training Administration, U.S. Department of Labor. Retrieved from http://www.doleta.gov/Youth_services/pdf/STEM_Report_4\%2007.pdf

26. Koballa, T. R., Gräber, W., Coleman, D., \& Kemp, A. C. (1999). Prospective teachers' conceptions of the knowledge base for teaching chemistry at the gymnasium. Journal of Science Teacher Education, 10(4), 269-286. 
27. Lachapelle, C. P., Cunningham, C. M., \& Oware, E. A. (2008). Engineering is Elementary: An evaluation of student outcomes from the PCET program. Boston, MA: National Center for Technological Literacy.

Retrieved from http://www.mos.org/eie/pdf/research/PCET_Evaluation_12_31_08.pdf

28. Lachapelle, C., Cunningham, C. M., John, T. J. L., Cannady, M., \& Keenan, K. (2010). An investigation of how two Engineering is Elementary curriculum units support student learning. Engineering is Elementary, The National Center for Technological Literacy, Museum of Science, Boston. Retrieved from http://www.mos.org/eie/pdf/research/Lachapelle_et_al_R1358.pdf

29. Lee, O., Adamson, K., Maerten-Rivera, J., Lewis, S., Thorton, C., \& LeRoy, K. (2008). Teachers' perspectives on a professional development intervention to improve science instruction among English language learners. Journal of Science Teacher Education, 19(1), 41-67.

30. Liu, W., Carr, R., \& Strobel, J. (2009). Extending teacher professional development through an online learning community: A case study. Journal of Educational Technology Development and Exchange, 2(1), 99-112.

31. Mandl, H., Gruber, H., \& Renkle, A. (1994). Problems of knowledge utilization in the development of expertise. In W. Nijhof \& J. Streumer (Eds.), Flexibility and cognitive structure in vocation education (pp. 291-305). Utrecht: Lemma.

32. Magnusson, S., Krajcik, J., \& Borko, H. (1999). Secondary teachers' knowledge and beliefs about subject matter and their impact on instruction. In J. Gess-Newsome \& N. G. Lederman (Eds.), Examining pedagogical content knowledge (pp. 95-132). Dordrecht: Kluwer Academic.

33. Mason, J., \& Spence, M. (1999). Beyond mere knowledge of mathematics: The importance of knowing-to act in the moment. Educational Studies in Mathematics, 38, 135-161.

34. Miller, G. A., \& Gildea, P. M. (1987). How children learn words. Scientific American, 257(3), 94-99.

35. National Academy of Engineering (NAE). (2008). Changing the conversation: Messages for improving public understanding of engineering. Committee on Public Understanding of Engineering Messages.

36. NGA (National Governors Association) Reports. (2007). Building a science, technology, engineering, and math agenda. Washington, DC: National Governors' Association.

37. Orton, R. E. (1993). Two problems with teacher knowledge. In A. Thompson (Ed.), Philosophy of education. Urbana, IL: Philosophy of Education Society. Retrieved from http://www.ed.uiuc.edu/EPS/PES-Yearbook/ 93_docs/ORTON.HTM

38. Patton, M. Q. (2002). Qualitative research and evaluation methods. Sage Publications, Inc.: California.

39. Patton, M. Q. (1990). Qualitative evaluation and research methods (2nd ed.). Newbury Park, CA: Sage.

40. Raizen, S. A., \& Michelsohn, A. M. (1994). The future of science in elementary schools: Educating prospective teachers. San Francisco, CA: Jossey-Bass.

41. Renkl, A., Mandl, H., \& Gruber, H. (1996). Inert knowledge: Analysis and remedies. Educational Psychologist, 31(2), 115-121.

42. Russell, T., \& Martin, A. K. (2007). Learning to teach science. In S. Abell \& N. Lederman (Eds.), Handbook of research on science education (pp. 1151-1178). Mahwah, NJ: Lawrence Erlbaum Associates.

43. Shulman, L. S. (1987). Knowledge and teaching: Foundations of the new reform. Harvard Educational Review, 57(1), 1-22.

44. Shulman, L. S. (1986). Those who understand: Knowledge growth in teaching. Educational Researcher, 15(2), 4-14.

45. Siorenta, A., \& Jimoyiannis, A. (2008). Physics instruction in secondary schools: An investigation of teachers' beliefs towards physics laboratory and ICT. Research in Science \& Technological Education, 26(2), 185-202.

46. Strauss, A., \& Corbin, J. (1998). Basics of qualitative research ( $2^{\text {nd }}$ ed.). Thousand Oaks: Sage Publications.

47. Strauss, A., \& Corbin, J. (1990). Basics of qualitative research: Grounded theory procedures and techniques. Newbury Park, CA: Sage.

48. U. S. Government Accountability Office. (2005). Higher education: Federal science, technology, engineering, and mathematics programs and related trends. Washington, DC: U. S. Government Accountability Office.

49. van Driel, J. H., De Jong, O., \& Verloop, N. (2002 ). The development of preservice chemistry teachers' pedagogical content knowledge. Science Education, 86, 572-590. 
50. Yasar, S., Baker, D., Robinson-Kurpius, S., Krause, S., \& Roberts, C. (2006). Development of a survey to assess K-12 teachers' perception of Engineers and familiarity with teaching design, engineering, and technology. Journal of Engineering Education, 95(3), 205-216. 